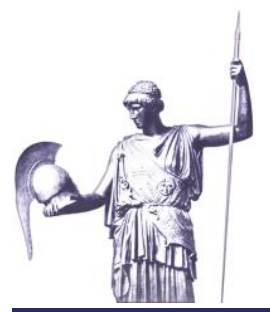

Connections: The Quarterly Journal

ISSN 1812-1101, e-ISSN 1812-2973

Петра Вейланд, Connections QJ 19, № 2 (2020): 100-112

https://doi.org/10.11610/Connections.rus.19.2.07

Рецензированная статья

\title{
Пандемия на Ближнем Востоке и в Северной Африке: размышления о текущих и будущих воздействиях
}

\section{Петра Вейланд}

Европейский центр исследований по вопросам безопасности им. Джорджа К. Маршалла, https://www.marshallcenter.org

Резюме: COVID-19 не пощадил ни один регион Глобального Юга и Глобального Севера. По очевидным причинам особенно сильно пострадали страны Глобального Юга. Это включает в себя регион Ближнего Востока и Северной Африки (БВСА), поскольку большинство его стран и обществ принадлежат к Глобальному Югу. Последствия вечной бедности, авторитаризма, коррупции и других серьезных долгосрочных недостатков означают, что этот вирус затронул общества, крайне плохо подготовленные для мобилизации огромных усилий, необходимых для противодействия не только ближайшим, но и огромным будущим вызовам. Поскольку долгосрочные недостатки управления и новые вызовы, порождаемые COVID-19, взаимно усиливают друг друга, поиск и проведение устойчивых решений на будущее становится еще более трудным - и более острой необходимостью. Эта перспектива не может оставаться без последствий для всего Средиземноморского региона - и для Европы. Партнерские отношения между Европой и странами Ближнего Востока и Северной Африки необходимы, как никогда. Чтобы эти партнерства были эффективными, они должны включать много новых заинтересованных сторон; они должны быть основаны на доверии и на принципе, что ответственность за региональную, национальную и особенно за безопасность человека должна быть общей.

Ключевые слова: MENA (БBCA), COVID-19, управление, международная помощь, партнерства Европа-БВСА. 


\section{Введение ${ }^{1}$}

Вряд ли найдется страна в мире, которая не пострадала сильно от пандемии COVID-19. Ситуация в США или Южной Корее показывает, что даже самые богатые и стабильные страны Глобального Севера не были обойдены стороной и борются за безопасность своего населения и функционирование своей экономики. Если Глобальному Северу чрезвычайно сложно контролировать пандемию, то страны Глобального Юга сталкиваются с еще более мучительной и трудной борьбой. Постоянная бедность, неэффективное управление и структурные недостатки означают, что большинство стран Глобального Юга неспособны успешно преодолеть кризис размеров COVID19 без надежной внешней помощи. В наименее развитых странах не только отсутствуют эффективные социальные системы, но и крайне слаба национальная экономика. Более того, правящие элиты чаще всего бывают популистскими, авторитарными и коррумпированными - все это мешает успешному решению этой огромной проблемы.

Беглый взгляд на имеющиеся статистические данные и исследования ${ }^{2}$ показывает, что большинство стран Ближнего Востока и Северной Африки (БВСА) не являются исключением в этом отношении. Показательным в этом отношении является Рейтинг недееспособности государств ${ }^{3}$ за 2019 год, который характеризует их как «крайне уязвимые» и помещает большинство ${ }^{4}$ из них в категорию «предупреждение» или "тревога». Арабский отчет о многомерной бедности ${ }^{5}$ «показывает, что из 286 миллионов человек, живущих в десяти странах, охваченных этим анализом, 116,1 миллиона $(40,6 \%)$ принадлежат к бедным домохозяйствам, из которых 38,2 миллиона $(13,4 \%)$ живут в крайней бедности». Другой важный документ, составленный Экономической и социальной комиссией Организации Объединенных Наций для Западной Азии (ЭСКЗА), дает четкие показатели многочисленных серьезных структурных недостатков. В нем подчеркивается, что «бедность

1 Выражаю благодарность Росио Корралес Рейон за ее ценные комментарии к этой статье.

2 Смотри, к примеру: UNDP, Arab Human Development Reports (AHDR), http://arabhdr.org; Joseph Bahout et al., Arab Horizons: Pitfalls and Pathways to Renewal (Washington, DC: Carnegie Endowment for International Peace, 2018), https://carnegie endowment.org/files/ArabHorizons_report_final.pdf; Adel Abdellatif and Ellen Hsu, UNDP's Regional Bureau for Arab States, "Grappling with a Crisis Like No Other: The Fragility of Arab Countries in the Face of COVID-19," Medium.com, March 31, 2020, https://medium.com/@UNDPArabStates/grappling-with-a-crisis-like-no-other-thefragility-of-arab-countries-in-the-face-of-COVID-19-a174b1017824.

32019 Fragile State Index, https://fragilestatesindex.org.

4 Исключениями являются страны Арабского залива, такие как Оман, ОАЭ или Катар.

5 United Nations Economic and Social Commission for Western Asia, Arab Multidimensional Poverty Report, No. E/ESCWA/EDID/2017/2; (Beirut: United Nations, 2017), c. 7, https://www.unescwa.org/sites/www.unescwa.org/files/publications/files/multidim ensional-arab-poverty-report-english.pdf. 
широко распространена, затрагивая более четырех из десяти домохозяйств и детей», и что "дополнительная четверть населения потенциально уязвима в плане бедности домохозяйств, а большинство бедных в НРС [среди арабских стран] крайне бедны». ${ }^{6}$

Все эти доклады показывают, что предварительные условия для успешного противодействия пандемии такого размаха, как COVID-19, и особенно ее долгосрочным последствиям, в регионе БВСА вряд ли имеются. Чтобы справиться с непосредственными последствиями пандемии, необходимы функционирующие национальные и местные органы власти и критически важная инфраструктура, средства и возможности, позволяющие им предоставлять необходимые общественные услуги, хорошо оснащенная система здравоохранения в распоряжении всех слоев общества, социальная инфраструктура, система обеспечения нуждающихся людей и здоровая экономика. Другими словами, предварительным условием для успешной борьбы с пандемией является высокий уровень национальной безопасности и безопасности человека, чего в регионе практически нет.

В этой статье более подробно рассматривается глубоко укоренившиеся политико-экономические недостатки, стоящие на пути успешного преодоления непосредственных и будущих последствий пандемии для человеческой и национальной безопасности в регионе БВСА. Учет этих исторических структурных недостатков будет sine qua non (непременным условием) любой успешной стратегии по смягчению долгосрочных последствий пандемии. Поскольку безопасность в регионе уже находится на рекордно низком уровне, существует высокий риск еще большей нестабильности и кризисов в качестве долгосрочного эффекта пандемии. Это не может оставаться без последствий для соседа БВСА - Европы. Поэтому в интересах Европы оказывать стратегически обоснованную поддержку. Немедленная денежная помощь там, где она необходима, безусловно, является ближайшей задачей. Тем не менее, любое среднесрочное и долгосрочное сотрудничество по преодолению последствий пандемии должно основываться на глубоком анализе, изложенном в этой статье.

\section{COVID-19 затронул регион, страдающий от постоянных структур- ных дефицитов}

На момент написания этой статьи еще слишком рано создавать полную картину масштабов долгосрочных последствий пандемии. Однако ясно то, что регион остро нуждался в реформе задолго до вспышки COVID-19, и эти структурные недостатки делают невозможным эффективное решение кри-

6 UN Economic and Social Commission for Western Asia, Arab Multidimensional Poverty Report, p. 21. 
зиса сегодня. Последствия пандемии станут еще одним тяжелым бременем, ${ }^{7}$ накладывая друг на друга и усугубляя огромные социально-экономические, финансовые, социальные и культурные проблемы, от которых регион страдает так давно. ${ }^{8}$

Давние неразрешенные недуги будут продолжать преследовать регион. За исключением региона Персидского залива, страны БВСА сильно пострадали в результате десятилетий неолиберальных реформ экономики, проводимых государством после обретения независимости. Структурная перестройка и приватизация экономики государств, постоянное сокращение социальных услуг, усиление авторитаризма и расширение секторов безопасности в сочетании с клановым капитализмом, резко растущим населением и перекосом демографической пирамиды привели к постоянному росту бедных слоев населения, сокращению среднего класса и появлению меньшинства сверхбогатых. Все это имело чрезвычайно пагубные последствия не только для граждан, но и для отношений между государством и обществом, для стабильности региона БВСА в целом и даже для Европы, как основного направления мигрантов. Давно прошли времена после обретения независимости, когда в социальных договорах между популистскими революционными политическими лидерами таких стран, как Египет, Ирак или Тунис, социальные услуги успешно обменивались на политическое согласие. Прошли те времена, когда щедрые средства из стран Персидского залива служили альтернативным источником финансирования для бедных соседних арабских государств. Безвозвратно ушли те времена, когда необеспеченное население нашло альтернативу сокращению государственных субсидий, став трудовыми мигрантами в нефтедобывающих странах Персидского залива. Несмотря на то, что положение по-прежнему намного лучше, чем в других странах, с резким сокращением доходов от нефти с 2014 года и отсутствием реальной альтернативы системе государства-рантье, ситуация стала нестабильной даже в странах Персидского залива. На протяжении десятилетий огромное богатство, накопленное в нефтяном секторе, позволяло правящей элите обменивать отстранение от политики и отсутствие любой критики королевской элиты на зажиточный образ жизни коренного арабского населения. По мере приближения конца нефтяной экономики, цена на нефть на мировых рынках упала до рекордно низкого

7 Marwan Muasher, "The Old Ways Won't Work," Diwan - Middle East Insights from Carnegie, April 9, 2020, https://carnegie-mec.org/diwan/81478.

8 Marwan Muasher, "The Next Arab Uprising. The Collapse of Authoritarianism in the Middle East," Foreign Affairs (November/December 2018), www.foreignaffairs.com/ articles/middle-east/2018-10-15/next-arab-uprising; Rami G. Khouri, "Comprehensive, Contentious, Convulsive, and Continuing: Some Observations on the 2010-2020 Arab Uprisings," Journal of Middle East Politics and Policy (A Harvard Kennedy School student publication, Spring 2020): 8-14, https://jmepp.hkspublications.org/wpcontent/uploads/sites/17/2020/03/Khouri.pdf. 
уровня, и никаких альтернативных стратегий обеспечения устойчивого будущего реализовано не было. Следовательно, темные тучи уже сгущались на горизонте прежде чрезвычайно богатых стран Персидского залива еще до вспышки пандемии.

Главный недостаток во всех странах БВСА - бедных или богатых - один и тот же. На протяжении десятилетий наследники популистских и светских политических лидеров после обретения независимости (а также королевские семьи) оказывались неспособными реализовать возможные решения для выхода из социально-экономического болота, описанного выше. В первую очередь заинтересованные в отражении любых угроз своему привилегированному политическому и экономическому статусу, исходящих от все более лишенных гражданских прав масс, они преобразовали систему управления во все более авторитарные и коррумпированные администрации и вложили значительные средства в расширение секторов безопасности своих стран, сделав так, что они в первую очередь служат интересам элит и бюрократии вместо того, чтобы серьезно заняться потребностями безопасности своих обществ.

Растущее недовольство населения все более неприемлемой ситуацией достигло апогея в 2011 году, когда арабские восстания потребовали уважения достоинства, хлеба и свержения режимов. Некоторые правящие элиты - особенно в королевствах Марокко, Иордании и Саудовской Аравии быстро отреагировали и удовлетворили некоторые из самых насущных потребностей своего населения. Тунис предпринял смелые шаги по удовлетворению потребностей тунисских мужчин и женщин. Однако этих мер оказалось во многом недостаточно. Другие авторитарные элиты в странах Ближнего Востока и Северной Африки выступили против требований населения, озвученных в 2011 году, с еще большими репрессиями, отсюда и полное опустошение, которое мы наблюдаем сегодня в Сирии, Ираке, Йемене и Ливии. Тем не менее, даже в сегодняшних репрессивных условиях, которые намного более ужасны, чем в 2011 году, народные протесты снова нарастают во многих странах БВСА, особенно в Ираке, Ливане, Иордании, Судане, Алжире и Тунисе.

Таков был, в общем и целом, политико-экономический ландшафт в странах Ближнего Востока и Северной Африки, когда разразился кризис COVID19: большие части региона охвачены бесконечным, крайним вооруженным насилием; почти ничего не было достигнуто в отношении новых социальных контрактов, уравновешивающих законные потребности населения в безопасности с необходимостью стабильности режима, ${ }^{9}$ экономики, все еще па-

9 Так в Индексе трансформации Бертельсманна (ВТІ) на 2020 год говорится о регионе БВСА: «Едва ли найдется хоть одна страна, которая действительно решает свои фундаментальные структурные проблемы: круги властовой элиты и широко распространенная коррупция; рост населения, особенно среди беднейших 
дающей, и культуры страха и огромного взаимного недоверия, определяющих отношения между политическими элитами и населением арабских стран. Короче говоря, когда разразился COVID-19, национальная безопасность и безопасность человека, свобода от страха и свобода от нужды были уже на рекордно низком уровне, и многие тысячи граждан в зонах конфликта погибли, были искалечены или страдали от посттравматического стрессового расстройства. Тысячи людей были брошены в тюрьмы за то, что требовали реформ, а молодые люди превратились в потерянное поколение, неспособные сыграть свою естественную роль, став способными и квалифицированными будущими лидерами своих стран.

Не следует забывать и о сотнях тысяч мужчин, женщин и детей, которые пытались найти индивидуальный путь выхода из затруднительного положения, став внутренне перемещенными лицами (ВПЛ) в своих странах или в качестве беженцев, населяющих перенаселенные лагеря в Ливане, Иордании или Турции. Будущее не сулит ничего хорошего и тем беженцам, которые уехали еще дальше от своих стран, и в конечном итоге прозябают в «горячих точках» EC, таких как греческие острова. ${ }^{10}$ Их судьба была уже до пандемии крайне мрачной. Со временем местное принимающее население перешло от изначально приветливого отношения ко все более враждебномулибо из-за того, что инфраструктура местного управления не была построена для размещения бесконечного числа мигрантов, либо из-за в целом растущего популизма и агитации против беженцев. Их затруднительное положение усугубляется неспособностью или нежеланием Европы, будь то на национальном или коллективном уровне, реализовывать долгосрочные решения для этих людей. Живя в чрезвычайно густонаселенных районах, что делает физическое дистанцирование невозможным, и страдая от нехватки воды, средств гигиены и санитарии, ${ }^{11}$ просители убежища, беженцы и ВПЛ относятся к тем слоям населения БВСА, которые наиболее подвержены риску заражения коронавирусом.

Короче говоря, все эти долгосрочные социальные недостатки делают любые попытки успешно справиться с пандемией весьма сложной задачей. Более того, многие авторитарные элиты уже используют меры по ограничению распространения пандемии, чтобы еще больше укрепить свои позиции

слоев; и неустойчивость общей безопасности», https://www.bti-project.org/en/ reports/regional-report-ENA.html.

10 Human Rights Watch, "Greece: Refugees Working to Protect Moria Camp from Covid19," April 22, 2020, https://www.hrw.org/hy/node/341138.

11 Justin Schon, "Protecting Refugees in the Middle East from Coronavirus: A Fight against Two Reinforcing Contagions," POMEPS Studies 39, Special Issue on the COVID19 Pandemic in the Middle East and North Africa (Washington, DC: George Washington University, Elliott School of International Affairs, April 2020), $\mathrm{http}: / /$ pomeps.org/protecting-refugees-in-the-middle-east-from-coronavirus-a-fightagainst-two-reinforcing-contagions. 
во власти в ущерб обществам. ${ }^{12}$ Борясь с огромным долгосрочным бременем пандемии у себя дома, всем странам Глобального Севера также придется переоценить свою способность и готовность оказывать достаточную помощь. При нарушении глобальных цепочек поставок будет иметь место дополнительное серьезное воздействие, скорее всего на продовольственную безопасность региона.

Помимо уровня национальной политической экономии, геополитическое измерение добавляет кризису еще один уровень сложности. После вторжения в Ирак в 2003 году, в странах Ближнего Востока и Африки наблюдается постепенный распад регионального геополитического порядка. Уход США оставил пространство, открытое для растущего числа региональных и глобальных игроков (особенно Ирана, России, ${ }^{13}$ Китая, ${ }^{14}$ Турции и стран Персидского залива), которые усиливают свое присутствие в регионе и поддерживают прокси-силы или государственные элиты с целью изменения геополитического ландшафта в свою пользу.

Все эти региональные и глобальные силы будут стремиться сохранить и расширить свое недавно завоеванное региональное влияние. Необходимость отвлекать национальные средства и возможности для борьбы с последствиями пандемии в своих странах не обязательно приведет к уходу из региона, а скорее к поиску новых механизмов сохранения влияния.

\section{Сосредоточение внимания на национальных государствах}

\section{и населении}

Хотя эта оценка в целом верна для всех стран региона БВСА, кризис определенно затронул каждую страну по-своему, отражаясь крайне неблагоприятно на ее общество, ее сельские и городские районы, ее отдельных граждан или их домохозяйств. Кроме того, по мере развития кризиса, каждый день приходит с новыми событиями, новыми чрезвычайными ситуациями и статистическими обновлениями, которые не могут быть описаны на этих

12 Nathan J. Brown, Intissar Fakir, and Yasmine Farouk, "Here to Stay? The Impact of the Coronavirus in the Middle East Has Led to Shifts in the Nature of Authoritarianism," Diwan - Middle East Insights from Carnegie, April 22, 2020, https://carnegiemec.org/diwan/81611; Sarah Yerkes, "Coronavirus Threatens Freedom in North Africa," Carnegie Endowment for International Peace, April 24, 2020, https://carnegie endowment.org/2020/04/24/coronavirus-threatens-freedom-in-north-africa-pub81625.

13 Dmitri Trenin, "Russia's Viral Calculations," Diwan - Middle East Insights from Carnegie, April 16, 2020, https://carnegie-mec.org/diwan/81575.

14 Guy Burton, "China and COVID-19 in MENA," POMEPS Studies 39, Special Issue on the COVID-19 Pandemic in the Middle East and North Africa (Washington, DC: George Washington University, Elliott School of International Affairs, April 2020): 25-28, https://pomeps.org/china-and-covid-19-in-mena. 
страницах. ${ }^{15}$ Тем не менее, можно выделить три основные категории стран и определенные сегменты населения БВСА, которые подвергаются определенному воздействию: зоны конфликтов и несостоятельные государства; относительно стабильные, экономически и структурно очень хрупкие страны; и, наконец, арабские страны-экспортеры нефти в регионе Персидского залива. ${ }^{16}$ Также необходим выход за пределы макроуровня национальных государств и включение микроуровня последствий пандемии для отдельных лиц и домохозяйств, поскольку они являются основным элементом любого общества. Если закрыть глаза на воздействие пандемии на микрокосм повседневной жизни, то будет невозможен анализ последствий для макроуровня национального государства и его стабильности.

Во-первых, это зоны конфликтов и несостоявшиеся государства - такие страны, как Ливия, Йемен, Ирак и Сирия, которые в течение многих лет были втянуты в гражданские войны и вооруженные конфликты как последствия арабских восстаний в 2011 году. Затяжные конфликты привели к почти полностью разрушенной инфраструктуре государственных и социальных служб; страны разделились на гибридные и динамичные констелляции конкурирующих государственных, негосударственных, полугосударственных и иностранных субъектов, борющихся с или против того, что когда-то было центральным правительством; экономика в руинах; молодое поколение (будущее любого общества) без надлежащего образования, исключенное из участия в принятии решений в своей стране или покинувшее страну. В эту категорию также входит перенаселенный сектор Газа, ${ }^{17}$ находящийся в условиях блокады со стороны Израиля. Больше всего от кризиса пострадали мирные жители, живущие в зонах конфликтов и несостоявшихся государствах. ${ }^{18}$

Затем есть относительно стабильные, но хрупкие страны. В эту категорию попадают Ливан, Иордания, Египет, Алжир и Тунис. С их большой численностью населения и слабой администрацией, каждая из них борется со своими собственными структурными недостатками. Хотя существующие правительственные и административные структуры предоставляют базо-

15 Для ежедневного бюллетеня новостей, связанных с COVID-19 на Ближнем Востоке, смотри ВВС Essential Media Insight Service, https://monitoring.bbc.co.uk.

16 Для анализа отдельных стран, смотри: POMEPS Studies 39, a special issue on the COVID-19 Pandemic in the Middle East and North Africa, April 2020: https://pomeps.org/wp-content/uploads/2020/04/POMEPS_Studies_39_Web.pdf.

17 Zaha Hassan and Hallaamal Keir, "U.S. Policy Response to Coronavirus in Gaza," Policy Outlook - Carnegie Endowment of International Peace, March 30, 2020, https://carnegieendowment.org/2020/03/30/u.s.-policy-response-to-coronavirus-ingaza-pub-81390.

18 Eric Goldstein and Amy Braunschweiger, "When Health Care Is Decimated By War: COVID-19 in the Middle East and North Africa," Human Rights Watch, April 16, 2020, accessed April 20, 2020, https://www.hrw.org/news/2020/04/16/when-health-caredecimated-war-COVID-19-middle-east-and-north-africa. 
вые услуги для борьбы с текущим воздействием пандемии, без остро необходимой помощи со стороны мирового сообщества эти страны вскоре столкнутся с чрезвычайно серьезными проблемами, если они не хотят перейти из состояния хрупкости в состояние развала. Это тем более важно, поскольку финансовая помощь стран Персидского залива резко сократилась из-за резкого падения цен на нефть. Уязвимость этих стран усугубляется тем фактом, что население, особенно молодое поколение, в значительной степени исключено из процесса принятия политических решений и не видит будущего в своих странах. В то время как сторонние наблюдатели склонны думать, что арабские восстания 2011 года были не более чем недолгой "Арабской весной», поколение восстаний на самом деле продолжало выражать свое недовольство, свои требования об обеспечении экономических возможностей, а также об их включении в политическую жизнь и подотчетности управления. Учась на прошлых ошибках, протестующие разработали новые сети и новые формы действий, чтобы их требования были услышаны.

Резкое сокращение доходов от нефтяного и туристического секторов ограничило даже богатым странам-экспортерам нефти возможность реализовать необходимые стратегии решения основных политико-экономических проблем. Большие доходы от нефти давали возможность поддерживать прекрасную систему здравоохранения в прошлом, что позволило администрациям государств Персидского залива сегодня успешно решать неотложные проблемы COVID-19, с которыми их граждане сталкиваются. Однако это не относится к большому количеству населения Персидского залива - трудовым мигрантам, включая мигрантов в сфере обслуживания. Опять же, ситуация усугубляется особыми проблемами, с которыми сталкивается каждая страна в отдельности, ${ }^{19}$ например высокой стоимостью участия Саудовской Аравии в войне в Йемене и потерей доходов от паломничества в хадж.

Не следует забывать, что кризис глубоко влияет на безопасность каждого отдельного гражданина мужского и женского пола, каждого домашнего хозяйства и многих местных сообществ. Безотлагательность удовлетворения их потребностей, особенно в наше время, является вопросом не только прав человека, но и будущего их стран. Это должно вызывать беспокойство и в Европе.

19 Смотри, к примеру: Netty Idayu Ismail, “Market Devouring Record Gulf Bonds Won't Touch Oman, Bahrain," Bloomberg, April 19, 2020, по состоянию на 20 апреля 2020, https://www.bloomberg.com/news/articles/2020-04-19/bond-market-devouringrecord-gulf-debt-won-t-touch-oman-bahrain; Vivian Nereim, "Saudi Arabia Looks at 'Painful Measures,' Deep Spending Cuts," Bloomberg, May 2, 2020, www.bloom berg.com/news/articles/2020-05-02/saudi-arabia-looking-at-painful-measures-deepspending-cuts. 
Практически полное бездействие экономики всех стран БВСА наиболее серьезно сказывается на тех, кто находится в нижней части социальной пирамиды. Чем дольше продолжается изоляция, тем сильнее страдают миллионы поденщиков, работающих в обширных неформальных секторах своих стран. ${ }^{20}$ Не имея возможности покидать свои дома, оставленные без ежедневного заработка и без социальной помощи, они все чаще не могут приносить еду к столу - что ставит их перед выбором: «смерть от вируса COVID-19 или смерть от голода» - либо игнорировать правила карантина и подвергать себя риску заражения и наказания, или голодать. ${ }^{21}$ Без их скудных доходов и без социальных услуг, предоставляемых правительством, НПО, негосударственные субъекты, вооруженные группы или религиозные организации становятся все более важными для удовлетворения потребностей этих людей. Услуги, предоставляемые такими организациями, могут иметь свою цену, поскольку они дают этим организациям возможность получить влияние. В лучшем случае, эти организации со временем будут включены в пользующиеся доверием структуры местного самоуправления. В худшем случае, помощь предоставляется при условии их присоединения к вооруженной группе.

Продолжающиеся блокировки и карантин, рост числа умерших, невозможность сводить концы с концами уже привели к серьезным психологическим, эмоциональным, физическим и сексуальным последствиям для большинства граждан БВСА, особенно для тех, кто живет в переполненных жилищах в районах трущоб или в лагерях беженцев. Среди наиболее уязвимых групп - дети и женщины, ВПл, беженцы и трудовые мигранты, 22 в том числе домашние рабочие с проживанием в семье. Домашнее насилие резко возрастает во всех обществах, пострадавших от коронавируса, но эти группы особенно уязвимы. Из-за запретов избегание домашнего насилия стало еще более сложным, поскольку учреждения, которые в обычное время помогают жертвам, такие как приюты для женщин, также были вынуждены резко сократить свои услуги. Кроме того, получить поддержку от полиции или судебных органов стало практически невозможно. В недавнем докладе ${ }^{23}$ при-

20 Относительно определения неформального сектора и статистических данных за период 1999-2007, смотри Friedrich Schneider, Andreas Buehn, and Claudio E. Montenegro, "Shadow Economies: All over the World: New Estimates for 162 Countries from 1999 to 2007," Policy Research Working Paper No. 5356 (The World Bank, July 2010), http://documents.worldbank.org/curated/en/3119914680371327 40/pdf/WPS5356.pdf.

21 Rana Taha and Dina Aboughazala, "COVID-19 Analysis: Can Arab World's Poorest Survive Stay at Home Calls?" Insight BBC Monitoring, April 13, 2020.

22 Mauro Testaverde, "Social Protection for Migrants during the COVID-19 Crisis: The Right and Smart Choice," World Bank Blogs, April 28, 2020, https://blogs.world bank.org/voices/social-protection-migrants-during-covid-19-crisis-right-and-smartchoice.

23 Hesham Shawish, “Covid 19 Analysis: Lockdown Shines Light on Domestic Abuse in 
водятся некоторые примеры домашнего насилия в Ливане. Можно ожидать, что ситуация будет похожей во всех обществах региона и за его пределами.

Еще одна особо уязвимая группа, о которой почти ничего не слышно, это сотни тысяч ВПЛ в зонах боевых действий. Закрытие внутренних границ представляет собой огромную дополнительную проблему для государственных служб или международных организаций при оказании помощи. Как и ВПЛ, местное сельское население сильно зависит от местных добровольных организаций, которые стараются изо всех сил, даже несмотря на то, что они плохо оснащены и недофинансированы. Как упоминалось ранее, ужасная ситуация может не оставить людям другого выбора, кроме как обратиться за помощью к какой-либо военизированной группе, которая затем может заставить их стать активными сторонниками воинствующей экстремистской группировки.

Пытаясь понять человеческие страдания, вызванные COVID-19, мы не можем забывать беженцев и лиц, ищущих убежища, в сильно переполненных лагерях в Греции ${ }^{24}$ или судьбу тех, кого перебрасывают из лагеря в лагерь в Турции - многие из них пришли из зон конфликтов в странах Ближнего Востока и Северной Африки.

\section{Региональная и международная помощь}

Короче говоря, национальные правительственные администрации вряд ли могут в достаточной степени бороться с последствиями коронавируса в своих странах и смягчать их последствия. Ситуация усугубляется тем, что в странах Ближнего Востока и Северной Африки отсутствуют скоординированные национальные ответные меры арабских стран по борьбе с пандемией на региональном уровне. Более того, региональные органы - Лига арабских государств, Организация исламских стран или Совет сотрудничества стран Персидского залива 25 - традиционно очень слабы и, следовательно, практически не могут помочь в нынешней ситуации.

Поскольку страны Глобального Севера также находятся под огромным давлением, чтобы обеспечить выживание их экономик, объем межправительственной помощи со стороны Глобального Севера может снижаться по ряду причин, в том числе вызванным пандемией серьезным глобальным экономическим спадом. Так что будущее не светлое. Растущий популизм и

Lebanon," BBC Monitoring: Insight, April 15, 2020, по состоянию на 16 апреля 2020. 24 Human Rights Watch, "Greece: Island Camps Not Prepared for Covid-19-Government Neglect Puts Lives at Risk," April 22, 2020, https://www.hrw.org/news/2020/04/ 22/greece-island-camps-not-prepared-COVID-19.

25 Смотри, однако, о помощи для удовлетворения непосредственных потребностей борьбы против пандемии: Matthew Hedges, "Authoritarian Exploitation of COVID19 in the GCC," POMEPS Studies 39, 35-37. 
односторонность действий также оказывают негативное влияние на международную солидарность, недавними примерами которых являются решение президента Соединенных Штатов прекратить финансирование ВОЗ или отказ большинства европейских стран разместить даже небольшое количество несовершеннолетних, без сопровождения взрослых, для проживания в «горячих точках» на греческих островах.

Международные и многосторонние организации, такие как МВФ, ВОЗ, G7 или EC, осведомлены о ситуации и рассматривают возможность оказания помощи. Однако огромный объем помощи, необходимой во всем мире, затрудняет оказание необходимой помощи даже этими организациями.

\section{Подведение итогов: вызовы будущего}

Успешная борьба с пандемией COVID-19 зависит не только от финансирования, от способных технократов, которые возглавят борьбу с пандемией, и от разумно функционирующей администрации. В конечном счете, выздоровление зависит от подотчетности, прозрачности и доверия, а также от участия и инклюзивности граждан-и все это под эгидой концепции совместной ответственности. Для этого необходимо участие населения и политическое руководство, искренне ставящее благополучие страны на первое место. Это предварительные условия для стран БВСА, чтобы успешно преодолеть тяжелые трудности восстановления после того, как вирус будет побежден. Другими словами: без значимого нового общественного договора ни одна администрация, ни правящая элита не могут успешно бороться с долгосрочными последствиями пандемии. Если всего этого не хватало еще до начала кризиса, трудно понять, как и без того крайне измученное население сможет нести дополнительные трудности, необходимые для восстановления своей страны. ${ }^{26}$ И все же, без выполнения этих условий, регион почти наверняка погрузится в еще большую дестабилизацию.

Даже если все эти предварительные условия будут выполнены, регион все равно будет нуждаться в солидарности внешних партнеров, искренне заинтересованных в мирных, процветающих соседях. Первым адресатом в этом отношении, безусловно, является Европа. Что необходимо, так это то, чтобы ЕС воплотил свои ценности, цели и действия, определенные в Глобальной стратегии внешней политики и политики безопасности Европейского союза, ${ }^{27}$ в мощные формы устойчивого взаимодействия.

Это предварительные условия для преодоления будущих последствий пандемии. Это также предварительные условия для того, чтобы регион мог

26 Muasher, "The Old Ways Won't Work."

27 "Shared Vision, Common Action: A Stronger Europe - A Global Strategy for the European Union's Foreign and Security Policy," June 2016, https://eeas.europa.eu/ archives/docs/top_stories/pdf/eugs_review_web.pdf. 
справиться с еще одним надвигающимся кризисом, даже более масштабным, чем COVID-19: последствиями изменения климата.

\section{Отказ от ответственности}

Выраженные здесь взгляды являются исключительно взглядами автора и не отражают точку зрения Консорциума оборонных академий и институтов изучения безопасности ПрМ, участвующих организаций или редакторов Консорциума.

Издание Connections: The Quarterly Journal, том 19, 2020 осуществляется при поддержке правительства Соединенных Штатов.

\section{Об авторе}

Петра Вейланд изучала исламские науки в Бонне, Германия. Она получила степень доктора философии по социальной антропологии ближневосточных обществ в Билефельдском университете, Германия. Она получила свою квалификацию путем участия во многих полевых исследованиях в регионе, во время преподавания в Академии Генерального штаба вооруженных сил Германии и Европейском центре исследований в области безопасности им. Джорджа К. Маршалла. Среди ее основных исследовательских интересов человеческое измерение безопасности и инновационные подходы к безопасности в Средиземноморском регионе. 